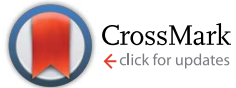

Cite this: RSC Adv., 2017, 7, 7619

\title{
Temperature-controlled solvent-free selective synthesis of tert-butyl peresters or acids from benzyl cyanides in the presence of the TBHP/ $\mathrm{Cu}(\mathrm{OAc})_{2}$ system $\dagger$
}

\author{
H. Hashemi, ${ }^{a}$ D. Saberi, ${ }^{\star b}$ S. Poorsadeghi ${ }^{\mathrm{c}}$ and Kh. Niknam ${ }^{\star a}$ \\ Solvent-free room temperature synthesis of tert-butyl peresters was achieved via copper-catalyzed \\ oxidative-coupling of benzyl cyanides with tert-butyl hydroperoxide in short reaction times. Various \\ derivatives of tert-butyl peresters were synthesized by this pathway in good to excellent yields. Further \\ investigation revealed that the above-mentioned protocol is effective for the synthesis of benzoic acid \\ derivatives when the reaction is conducted at $80^{\circ} \mathrm{C}$, under the same reaction conditions.
}

Received 8th December 2016

Accepted 2nd January 2017

DOI: 10.1039/c6ra27921j

www.rsc.org/advances

\section{Introduction}

Providing new synthetic methods or promoting previously reported ones is one of the main challenges to the synthetic chemists. Many efforts have been made to achieve a variety as well as green and eco-friendly synthetic pathways for important and widely used organic compounds. In recent years, oxidative coupling reactions in which two nucleophiles, in the presence of an external oxidant, are coupled together have been developed. ${ }^{1}$ In this type of reaction, since only nucleophiles are used, unlike traditional methods that involve either electrophiles or nucleophiles, synthetic procedures will be more efficient and waste production will be minimized.

tert-Butyl peresters are an important class of organic compounds because of their participation in organic transformations in particular as oxidants in oxidation reactions. ${ }^{2}$ Traditionally, tert-butyl peresters are prepared from carboxylic acids or their analogous benzoyl chlorides with tert-butyl hydroperoxide in the presence of base (Scheme 1, eqn (a)). ${ }^{3}$ In 2011, a distinguish methodology by high atom economy and free of base was disclosed by Wan et al. for synthesis of tert-butyl peresters. ${ }^{4}$ They reported on water $\mathrm{Bu}_{4} \mathrm{NI}$-catalyzed oxidative coupling of aldehydes with TBHP at $40{ }^{\circ} \mathrm{C}$ (Scheme 1, eqn (b)). The same procedure has recently been reported by Wang et al. in which alcohols is coupled with TBHP for synthesis of tertbutyl peresters (Scheme 1, eqn (c)). ${ }^{5}$ Due to their importance as well as the low number of reported procedures, development of

${ }^{a}$ Department of Chemistry, Faculty of Sciences, Persian Gulf University, Bushehr 75169, Iran. E-mail: niknam@pgu.ac.ir

${ }^{b}$ Fisheries and Aquaculture Department, College of Agriculture and Natural Resources, Persian Gulf University, Bushehr 75169, Iran. E-mail: saberi_d@pgu.ac.ir ${ }^{c}$ Chemistry Department, Tarbiat Modares University, Tehran, Iran

$\dagger$ Electronic supplementary information (ESI) available. See DOI: $10.1039 /$ c6ra27921j synthetic methods for tert-butyl peresters is interest. Here we report a new synthetic pathway for the preparation of tert-butyl peresters via copper-catalyzed oxidative coupling of benzyl cyanides with TBHP (Scheme 1, eqn (d), path I). Performing under solvent-free conditions at room temperature in low reaction times make interest this transformation. Moreover, we found that when this reaction is conducted at $80{ }^{\circ} \mathrm{C}$, benzoic acid derivatives will be predominant products (Scheme 1, eqn (d), path II).

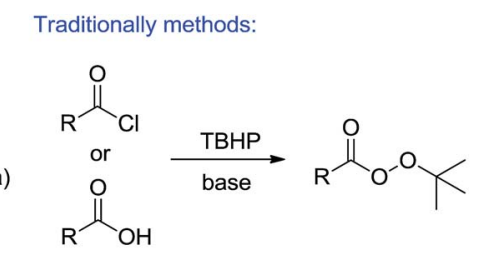

Oxidative-coupling methods

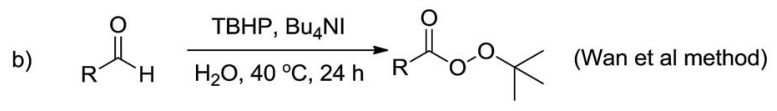

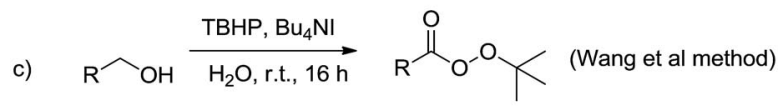

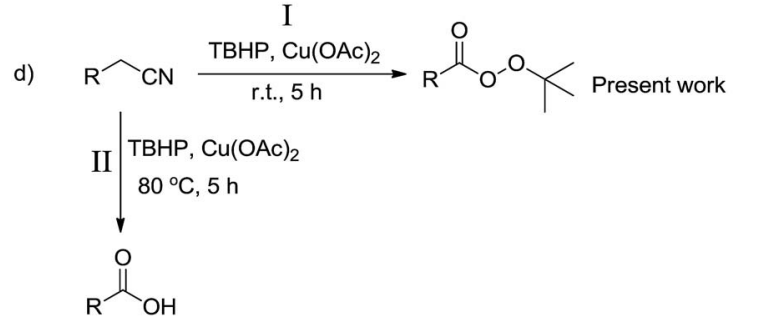

Scheme 1 Approaches for synthesis of tert-butyl peresters. 


\section{Results and discussion}

Following the benzyl cyanide oxidation in the presence of $\mathrm{Cu}(\mathrm{OAc})_{2} / \mathrm{TBHP}$ system, a unknown product was obtained in $40 \%$ yield that after identification turned out to be tert-butyl perbenzoate. As mentioned above, because of the gravity of this class of compounds, efforts were made to raise efficiency by changing the reaction conditions. The results are summarized in Table 1. As can be seen in this table, the pre-starter reaction was performed between benzyl cyanide $(1 \mathrm{mmol})$ and TBHP (70 wt $\%$ in $\left.\mathrm{H}_{2} \mathrm{O}, 1 \mathrm{mmol}\right)$ in the presence of $\mathrm{Cu}(\mathrm{OAc})_{2}(10 \mathrm{~mol} \%)$ as catalyst under solvent-free conditions at room temperature. Other copper salts such as $\mathrm{CuCl}_{2}, \mathrm{CuCl}, \mathrm{CuI}$, as well as TBAI also worked for this reaction, albeit with lower yields (Table 1, entries 2-5). Performance of $\mathrm{FeCl}_{2}$ for this transformation was weaker than copper salts (Table 1 , entry 6). Notably, $\mathrm{NiCl}_{2}$ showed no conversion (Table 1, entry 7 ). The experiment conducted under catalyst-free conditions showed that the catalyst has an important role in this reaction (Table 1, entry 8). Further investigation revealed that the ratio between the reactants is very important. The $1: 4$ ratio of benzyl cyanide to TBHP gave the highest yield (Table 1, entries 9-12). By increasing the amount of the catalyst to $20 \mathrm{~mol} \%$, the yield did not change, while by reducing it to $5 \mathrm{~mol} \%$, efficiency was decreased with $50 \%$ (Table 1, entries 13 and 14). Then, the effect of solvents on the reaction performance was evaluated. When the reaction was

Table 1 The tests for achieving to the optimum conditions ${ }^{a}$

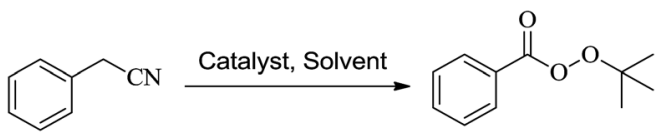

\begin{tabular}{lllll}
\hline Entry & Solvent & Catalyst $(\mathrm{mol} \%)$ & TBHP $(\mathrm{mmol})$ & Yield $^{b}(\%)$ \\
\hline 1 & - & $\mathrm{Cu}(\mathrm{OAc})_{2}(10)$ & 1 & 40 \\
2 & - & $\mathrm{CuCl}_{2}(10)$ & 1 & 30 \\
3 & - & $\mathrm{CuCl}(10)$ & 1 & 35 \\
4 & - & $\mathrm{CuI}(10)$ & 1 & 37 \\
5 & - & $\mathrm{TBAI}(10)$ & 1 & 20 \\
6 & - & $\mathrm{FeCl}(10)$ & 1 & 10 \\
7 & - & $\mathrm{NiCl}_{2}(10)$ & 1 & - \\
8 & - & - & 1 & - \\
9 & - & $\mathrm{Cu}(\mathrm{OAc})_{2}(10)$ & 2 & 60 \\
10 & - & $\mathrm{Cu}(\mathrm{OAc})_{2}(10)$ & 3 & 70 \\
11 & - & $\mathrm{Cu}(\mathrm{OAc})_{2}(10)$ & 4 & 80 \\
12 & - & $\mathrm{Cu}(\mathrm{OAc})_{2}(10)$ & 6 & 80 \\
13 & - & $\mathrm{Cu}(\mathrm{OAc})_{2}(10)$ & 4 & 80 \\
14 & - & $\mathrm{Cu}(\mathrm{OAc})_{2}(10)$ & 4 & 50 \\
15 & $\mathrm{H}_{2} \mathrm{O}$ & $\mathrm{Cu}(\mathrm{OAc})_{2}(10)$ & 4 & 50 \\
16 & $\mathrm{CH}{ }_{3} \mathrm{CN}$ & $\mathrm{Cu}(\mathrm{OAc})_{2}(10)$ & 4 & 50 \\
17 & $\mathrm{DMF}$ & $\mathrm{Cu}(\mathrm{OAc})_{2}(10)$ & 4 & 5 \\
18 & $\mathrm{EtOH}$ & $\mathrm{Cu}(\mathrm{OAc})_{2}(10)$ & 4 & 30 \\
19 & EtOAc & $\mathrm{Cu}(\mathrm{OAc})_{2}(10)$ & 4 & 30 \\
$20^{c}$ & - & $\mathrm{Cu}(\mathrm{OAc})_{2}(10)$ & 4 & 40 \\
$21^{d}$ & - & $\mathrm{Cu}(\mathrm{OAc})_{2}(10)$ & 4 & 5
\end{tabular}

${ }^{a}$ Benzyl cyanide $(1 \mathrm{mmol})$, under air atmosphere at room temperature.

${ }^{b}$ Isolated yield. ${ }^{c}$ At $50{ }^{\circ} \mathrm{C}$. ${ }^{d}$ The reaction was performed at $80{ }^{\circ} \mathrm{C}$ and benzoic acid was isolated as the main product in $85 \%$ yield. carried out in the solvents such as $\mathrm{H}_{2} \mathrm{O}, \mathrm{CH}_{3} \mathrm{CN}$, DMF, EtOH, and EtOAc, the efficiency was lower than that of solvent-free conditions (Table 1, entries 15-19).

As a last resort, the effect of temperature was studied and some interesting results were obtained. As temperature rise to $80{ }^{\circ} \mathrm{C}$, the efficiency was sharply down, in return benzoic acid was isolated with high efficiency (Table 1, entries 20 and 21). However this also will be a new and effective procedure for benzoic acid derivatives synthesis.

After optimization, in order to establish the scope of the procedure, a wide range of benzyl cyanides were subjected to the reaction conditions. The results are shown in Fig. 1. As seen is this figure, various derivatives of benzyl cyanide bearing halogen and electron-donating substituents, at different position of aromatic ring, were converted to the corresponding tertbutyl peresters in moderate to good yields (Fig. 1, 1a-j). 4-Cyanobenzyl cyanid was also successful in this transformation and product $1 \mathrm{k}$ was obtained in $65 \%$ yield. 4 -Nitrobenzyl cyanide was failed to this reaction and the corresponding product was formed in trace (Fig. 1, 11). When 4-(methylthio)benzyl cyanide was subjected to the reaction conditions, the desired perester (Fig. 1, 1m) was obtained in $60 \%$ yield and sulfide substituent that is susceptible to oxidation to sulfoxide, remained intact. Heteroaromatic and polycyclic cyanides, that is, thiophen-2-ylacetonitrile and naphthalen-2-yl-acetonitrile, also were condensed into the corresponding tert-butyl peresters $1 \mathbf{n}$ and 10 in high yields.

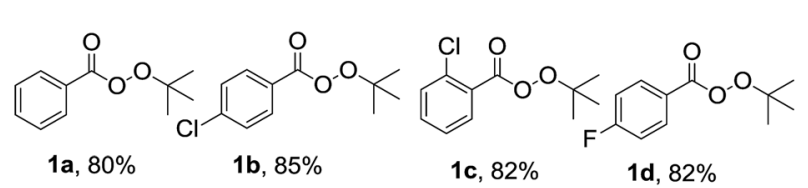<smiles>CC(C)(C)OOC(=O)c1ccc(Br)cc1</smiles><smiles>Cc1ccccc1C(=O)OOC(C)(C)C</smiles><smiles>Cc1ccc(C(=O)OOC(C)(C)C)cc1</smiles><smiles>COc1cccc(C(=O)OC(C)(C)C)c1</smiles><smiles>CCOc1ccc(C(=O)OOC(C)(C)C)cc1</smiles><smiles>COc1cc(C(=O)OOC(C)(C)C)cc(OC)c1OC</smiles><smiles>CC(C)(C)OOC(=O)c1ccc(C#N)cc1</smiles><smiles>CC(C)(C)OOC(=O)c1ccc([N+](=O)[O-])cc1</smiles><smiles>CSc1ccc(C(=O)OOC(C)(C)C)cc1</smiles><smiles>CC(C)(C)OOC(=O)c1cccs1</smiles><smiles>CC(C)(C)OOC(=O)c1ccc2ccccc2c1</smiles><smiles>CC(C)(C)OC(=O)c1ccccc1C(=O)OC(C)(C)C</smiles>

Fig. 1 Substrate scope. Reaction conditions: benzyl cyanide derivatives $(1 \mathrm{mmol}), \mathrm{TBHP}(4 \mathrm{mmol}), \mathrm{Cu}(\mathrm{OAc})_{2}(10 \mathrm{~mol} \%)$, r.t., reaction time: $5 \mathrm{~h}$; the yields refer to the isolated pure products. 
Moreover, 1,2-phenylenediacetonitrile was converted to the product 1p in which both benzylic groups have become to the tert-butyl perester group. All the products $\mathbf{1 a}-\mathbf{p}$ was identified by elemental analysis and FTIR, ${ }^{1} \mathrm{H}$ and ${ }^{13} \mathrm{C}-\mathrm{NMR}$ spectra.

As was considered above, when the model reaction was conducted at $80{ }^{\circ} \mathrm{C}$, benzoic acid was obtained in $85 \%$ yield. Therefore this protocol was extended for the synthesis of benzoic acid derivatives. Optimized conditions for synthesis of tert-butyl peresters were the best for acids so. And by changing the amount of oxidant and catalysts, as well as increasing the temperature to $100{ }^{\circ} \mathrm{C}$, the yield was not improved. Worthy of note is that, when sodium hypochlorite (NaOCl), di tert-butyl peroxide (DTBP), and $m$-chloro perbenzoic acid ( $m$ CPBA) was used instead of TBHP, no acid was formed and benzyl cyanide was isolated quantitative. Aliphatic cyanides were not successful in this transformation. In a typical experiment, when propionitrile was subjected to the reaction conditions, the reaction was not performed. Fig. 2 shows the structures of acids synthesized by this method. As can be seen in this figure, without depending on the type and position of substitution, the acids were derived with the high and neck-to-neck efficiency.
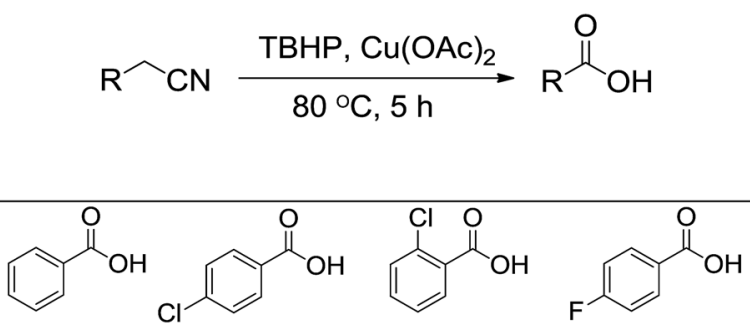

2a, $85 \%$ 2b, $83 \%$

2c, $80 \%$

2d, $78 \%$<smiles>COc1cccc(C(=O)O)c1</smiles>

$2 \mathrm{e}, 80 \%$

2f, $70 \%$

$2 \mathrm{~g}, 85 \%$

$2 \mathrm{~h}, 73 \%$<smiles>COc1cc(C(=O)O)cc(OC)c1O[14CH3]</smiles>

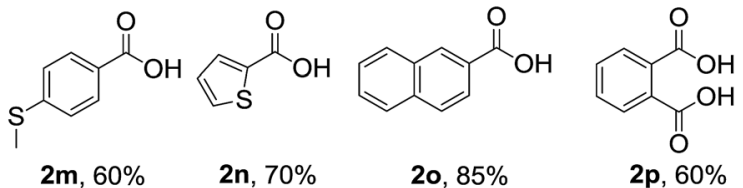

Fig. 2 The structures of the synthesized acids. Reaction conditions: benzyl cyanide derivatives ( $1 \mathrm{mmol}), \operatorname{TBHP}(4 \mathrm{mmol}), \mathrm{Cu}(\mathrm{OAc})_{2}(4$ mol\%), $80^{\circ} \mathrm{C}$, reaction time: $5 \mathrm{~h}$; the yields refers to the isolated pure products.
1)<smiles>NC(=O)c1ccccc1</smiles>

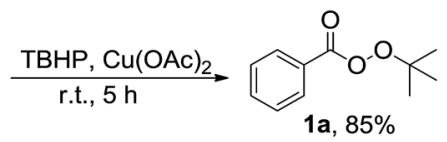

2)<smiles>N#CCc1ccccc1</smiles>

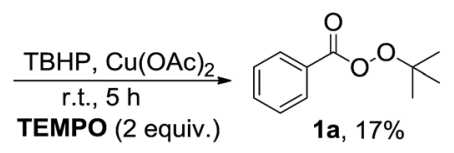

Scheme 2 Control experiments into the reaction mechanism.

From the viewpoint of reaction mechanism, since the benzyl cyanide is prone to oxidation into the benzoyl cyanide in the presence of TBHP, ${ }^{6}$ therefore reaction of benzoyl cyanide was investigated under the same reaction conditions to obtain a plausible mechanism (Scheme 2, eqn (1)). Formation of perester 1a in high yield showed that benzoyl cyanide can be impressive intermediate in this transformation. Moreover, the sharp decrease of efficiency in the presence of TEMPO, a known radical scavenger, revealed that radicals could be involved in the reaction pathway (Scheme 2, eqn (2)). In addition, the presence of free cyanide anion has been proven by the use of indicator paper (see ESI $\dagger$ ). ${ }^{6 c-f}$

Based on the above results and related works, ${ }^{7}$ the mechanism depicted in Scheme 3 is proposed for this transformation. Initially, the copper(II) species donates an electron to TBHP to generate a tert-butoxyl radical and a copper(III) species. ${ }^{7 b}$ The latter abstracts an electron from another molecule of TBHP and gives the original copper(II) species along with a tert-butyl peroxy radical. The tert-butoxyl radical could then abstract a hydrogen atom from the benzyl cyanide to generate the radical I which couples with the tert-butyl peroxy radical, affording a perester intermediate II. This intermediate can then be converted to the benzoyl cyanide III with the loss of tert-butanol. Benzoyl cyanide can be transformed to the corresponding tert-butyl perester, tert-butyl benzoate, or acid via nucleophilic attack by tert-butyl hydroperoxide, tert-butanol or water respectively. Worthy of note is that tert-butyl benzoate was observed in some experiments shown in Table 1.

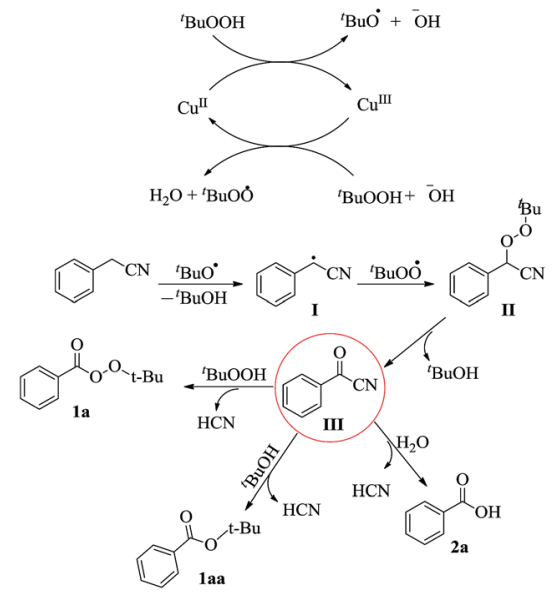

Scheme 3 Proposed mechanism. 


\section{Conclusions}

In conclusion an effective and temperature-controlled protocol was developed for the synthesis of tert-butyl peresters and benzoic acids from benzyl cyanides in the presence of $\mathrm{Cu} / \mathrm{TBHP}$ catalytic system. Various derivatives of tert-butyl peresters were synthesized in high yields under solvent-free conditions at room temperature. Benzoic acids were prepared under the same conditions with a slightly modified procedure, in which the reaction temperature was increased to $80^{\circ} \mathrm{C}$.

\section{Acknowledgements}

We are thankful to Persian Gulf University Research Council for partial support of this work.

\section{Notes and references}

1 (a) C. Liu, H. Zhang, W. Shi and A. Lei, Chem. Rev., 2011, 111, 1780; (b) W. Shi, C. Liu and A. Lei, Chem. Soc. Rev., 2011, 40, 2761; (c) C.-J. Li, Acc. Chem. Res., 2009, 42, 335; (d) M. Klussmann and D. Sureshkumar, Synthesis, 2011, 353.

2 (a) W. Ando, Organic peroxides, Wiley-interscience, New York, 1992; (b) L. Wang, X. Liu and Y. Li, Macromolecules, 1998, 31, 3446; (c) S. N. Gupta, I. Gupta and D. C. Neckers, J. Polym. Sci., Polym. Chem. Ed., 1981, 19, 103; (d) P. C. Montevecchi, A. Manetto, M. L. Navacchia and C. Chatgilialoglu, Tetrahedron, 2004, 60, 4303; (e) B. K. Shah and D. C. Neckers, J. Am. Chem. Soc., 2004, 126, 1830; $(f)$ F. Formaggio, M. Crisma, L. Scipionato, S. Antonello, F. Maran and C. Toniolo, Org. Lett., 2004, 6, 2753; $(g)$ Y. Li, S. Niu, B. Sun, S. Liu, X. Liu and Y. Che, Org. Lett., 2010, 12, 3144; (h) D. A. Powell and H. Fan, J. Org. Chem., 2010, 75, 2726; (i) M. T. Rispens, C. Zondercu and B. L. Feringa, Tetrahedron: Asymmetry, 1995, 6, 661; (j) Y. Kohmura and
T. Katsuki, Tetrahedron Lett., 2000, 41, 3941; (k) J. Eames and M. Watkinson, Angew. Chem., 2001, 113, 3679-3683; Angew. Chem., Int. Ed., 2001, 40, 3567; (l) A. V. Malkov, M. Bella, V. Langer and P. Koĉovský, Org. Lett., 2000, 2, 3047; $(\mathrm{m})$ M. B. Andrus and Z. Zhou, J. Am. Chem. Soc., 2002, 124, 8806.

3 (a) N. Milas and D. M. Surgenor, J. Am. Chem. Soc., 1946, 68, 642; (b) S. L. Silbert and D. Swern, J. Am. Chem. Soc., 1959, 81, 2364; (c) N. A. Milas, D. G. Orphanos and R. J. Klein, J. Org. Chem., 1964, 29, 3099; (d) M. Y. Lu, R. Bao, W. Liu and Y. Li, J. Org. Chem., 1995, 60, 5341; (e) Y. Hamada, A. Mizuno, T. Ohno and T. Shioiri, Chem. Pharm. Bull., 1984, 32, 3683.

4 W. Wei, C. Zhang, Y. Xu and X. Wan, Chem. Commun., 2011, 47, 10827.

5 H. Zhang, D.-Q. Dong, S.-H. Hao and Z.-L. Wang, RSC Adv., 2016, 6, 8465.

6 (a) S.-I. Murahashi, T. Naota and T. Kuwabara, Synlett, 1989, 62; (b) B. M. Choudary and P. N. Reddy, J. Mol. Catal. A: Chem., 1996, 112, 385; (c) Y. Luo, Q. Wen, Z. Wu, J. Jin, P. Lu and Y. Wang, Tetrahedron, 2013, 69, 8400; (d) L. Zhang, Q. Wen, J. Jin, C. Wang, P. Lu and Y. Wang, Tetrahedron, 2013, 69, 4236; (e) J. Jin, Q. Wen, P. Lu and Y. Wang, Chem. Commun., 2012, 48, 9933; $(f)$ Q. Wen, J. Jin, Y. Mei, P. Lu and Y. Wang, Eur. J. Org. Chem., 2013, 4032.

7 (a) D. Saberi, F. Shojaeyan and K. Niknam, Tetrahedron Lett., 2016, 57, 566; (b) N. Khatun, S. K. Santra, A. Banerjee and B. K. Patel, Eur. J. Org. Chem., 2015, 1309; (c) J. Wang, C. Liu, J. Yuan and A. Lei, Angew. Chem., Int. Ed., 2013, 52, 2256; (d) S. C. Ghosh, J. S. Y. Ngiam, C. L. L. Chai, A. M. Seayad, T. T. Dang and A. Chen, Adv. Synth. Catal., 2012, 354, 1407; (e) W. Wei, C. Zhang, Y. Xu and X. Wan, Chem. Commun., 2011, 47, 10827. 